Síntese - Rev. de Filosofia

v. 35 N. 112 (2008): 239-254

\title{
ÉTICA E SOCIABILIDADE: PUFENDORF E A HERANÇA HOBBESIANA
}

Luiz Felipe Netto de Andrade e Silva Sahd*

Resumo: O presente artigo tem como objetivo reconstruir argumentos centrais desenvolvidos por Samuel Pufendorf. Pufendorf opera um compromisso explícito entre Hobbes e a lei natural tradicional. De Hobbes, ele retém a doutrina individualista do contrato social quanto ao direito de governar; mas rejeita categoricamente sua doutrina da soberania, em proveito de um código laico da lei natural que expõe em detalhes em seus livros. Segundo o argumento de Pufendorf, na origem todos os homens viviam num "estado de natureza" em que eram livres, iguais e sem governo. Por conseguinte, todo governo provém de um contrato social, como ensinou Hobbes. Contudo, embora os homens sejam natural mente apolíticos, eles não são naturalmente egoístas, mas ao contrário sociais e sociáveis. Desde então, seu estado natural é um estado social e pacífico, em que podiam aplicar e aplicavam a lei natural tal como a descobriu sua razão.

Palavras-chave: Estado de natureza, lei natural, sociabilidade, soberania.

Abstract: The present article aims at reconstructing Samuel Pufendorf's central argument. Pufendorf works out an explicit compromise between Hobbes and the traditional natural law. He accepts Hobbe's individualistic theory of social contract regarding the right to govern, but emphatically rejects Hobbes' doctrine of sovereignty, preferring a secular natural law that he discussed in great detail in his books. According to Pufendorf, all individuals originally lived in a "state of nature" in which they were free, equal, and

Departamento de Filosofia da Universidade F ederal de U berlândia/MG. Artigo submetido a avaliação no dia 23/06/2006 e aprovado para publicação no dia 23/03/2007. 
ungoverned. Like Hobbes, he believed that all government arises from a social contract. However, although men are naturally apolitical, they are not naturally selfish but, on the contrary, social and sociable. Therefore, their natural state is a social and peaceful one where the law of nature can be applied, and is indeed applied, when guided by reason.

Key words: State of nature, natural Iaw, sociability, sovereignty.

mbora as principais teorias e sistemas do direito natural moderno não estejam de acordo sobre pontos importantes como as caracterís ticas que envolviam as narrativas do estado de natureza, a significação do pacto social e o fundamento da obrigação, elas acreditavam porém no ideal de justiça imposto ao Estado e não dependente da vontade arbitrária dos homens. Como na Antigüidade e na Idade Média um problema se põe aos juristas e filósofos dos séculos XVII e XVIII: a justiça é uma convenção ou uma lei absoluta? Ela é uma invenção dos homens, ou uma ordem da razão eterna? Existe em si? Ou é apenas uma relação arbitrária e variável, mudando com o tempo e os lugares? Há um direito e, por conseguinte, há direitos? Ou o único direito é o direito do mais forte? $\mathrm{O}$ problema é fundamental. Trata-se de saber se o direito é uma criação do Estado (ou da sociedade), se todo e qualquer direito emana de um legislador ou se, ao contrário, existe regras de justiça que se impõem aos governantes, regras absolutas, imutáveis e universais que dominam o Estado e inspiram o direito positivo. Há no fundo da alma humana uma necessidade incoercível de justiça? A razão não indica certas regras imutáveis, princípios essenciais que devem inspirar o legislador?

A tribui-se ao direito natural moderno o caráter de ser filosófico, pois os seus teóricos acreditavam absolutamente na razão para deduzir o direito da natureza das coisas. Eles acreditavam poder determinar o sistema completo de código de regras universais envolvendo o conjunto das instituições e das atividades do homem. À exceção de Pufendorf, imediatamente admoestado por Leibniz, e de Christian Thomasius, todos os representantes do jusnaturalismo moderno ainda confundem direito e moral ${ }^{1}$. O direito natural se estende indistintamente às ações internas e externas do homem, envolve o conjunto de seus deveres. Ora, os preceitos concernentes ao amor, amor de Deus, amor do próximo e amor de si, advêm da moral e não da justiça.

\footnotetext{
${ }^{1}$ A compreensão desta separação não elimina uma relação estreita entre ambos. Como escreve Michel Villey: "em filosofia do direito, tudo é solidário, e moral e direito são tão vizinhos que nada do que acontece com um deixa de repercutir no outro" (VILLEY, M., A formação do pensamento jurídico moderno (trad. de C. Berliner), São Paulo: Martins Fontes, 2005, p.340).
} 
A existência do direito natural uma vez admitida, portanto, duas questões fundamentais se colocam ao filósofo do direito: como conhecer a justiça objetiva? Qual será o fundamento da obrigação de fazer ou não fazer o que manda o direito natural? Em seus contornos mais gerais, os sistemas defendem a possibilidade do direito natural ser conhecido somente pelas luzes da razão, embora sejam reforçados pela revelação. Há entre os primeiros representantes jusnatural istas modernos divergências consideráveis quanto à segunda questão: Hobbes faz repousar o direito sobre o poder irresistível, Grotius sobre a natureza das coisas, Pufendorf sobre a vontade de um superior ao mesmo tempo forte e justo (e não sobre a vontade arbitrária de um superior, como pretendia Leibniz), Leibniz sobre a razão de Deus e a natureza das coisas. Tal é o estado da questão, no momento em que Pufendorf publica o seu D e jure naturae et gentium. Vejamos como o autor alemão resolve tal problemática.

A construção teórica do texto está baseada em dois princípios presentes no conjunto da obra de Pufendorf, são eles: a sociabilidade e a utilidade. No De jure naturae o autor afirma que a natureza humana exige dos indivíduos a convivência pacífica com outros indivíduos da mesma espécie ao manter e incrementar a sociabilidade de todos. A observação da natureza mostra que o homem é um ser tal hado para viver em sociedade, pois a sua constituição física indica claramente que ele foi feito para viver com os outros numa relação societária. Por um lado, ele tem numerosas necessidades naturais, por outro, a natureza não o dotou diretamente dos meios indispensáveis para satisfazer a essas necessidades. A o contrário de al guns animais que, sem sacrificar suas necessidades naturais, podem viver sozinhos, fora do estado social, o homem só pode suprir suas necessidades de modo satisfatório associando-se a outros homens. O estado de sociedade é uma necessidade lógica decorrente do fato de que as necessidades naturais do homem superam as possibilidades das quais dispõe para satisfazêlas sozinho². O fim almejado pelos seres humanos consiste em tornar efetiva a existência natural e irrenunciável do modo de ser do homem de viver em sociedade pacificamente: “Com estas premissas, escreve Pufendorf, parece que a lei natural fundamental é a seguinte: cada homem deve cultivar e manter na medida do possível a sociabilidade" 3 . Embora a finalidade do homem seja realizar o atributo por excelência da condição humana, a socialitas, os indivíduos que vemos diante de nós são inconstantes e egoístas (homens pecadores), mais preocupados com os próprios interesses e

\footnotetext{
${ }^{2}$ Cf. SCHINO, A., II Pensiero Politico di Pufendorf, Roma: Editori Laterza, 1995, p.2532.

3 Texto latino: "Inde fundamentalis lex naturae isthaec erit: cuilibet homini, quantum in se, colendam \& conservandam esse pacificam adversus alios socialitatem" (PUFENDORF, S., Gesammelte Werke, Band 4.1, De jure naturae et gentium (Líber primus - Líber quartus), herausgegeben von F. Böhling, Berlin: Akademie Verlag, 1998, II, III, §15).
} 
movidos por paixões muito pouco dignificantes. Como dar conta deste intervalo entre a natureza do homem tal como ela realmente é e a natureza tal como deveria ser? Se Pierre Laurent tem razão ao defender a tese de um "antropocentrismo moderado" na doutrina de Pufendorf, pode-se falar então que a sociabilidade, no seu sentido mais profundo, vincula estreitamente "o ser individual do homem ao seu ser em relação"4. Por princípio, Pufendorf recusaria um tratamento da condição humana a partir da sua individualidade absoluta, ela teria somente um valor relativo na medida em que dependeria da sociedade.

Pufendorf empreende uma retomada do princípio fundamental do direito de natureza segundo o método da ciência natural, o método analítico5. Ao praticar este método, porém, o autor decompõe a natureza humana em três elementos básicos para determinar a lei de seu ser. Estes componentes sintetizados na socialitas são: o amor sui (o amor de si ou o impulso de autoconservação), a imbecillitas e a naturalis indigentia, e a pravitas animi, que incita o homem a prejudicar o seu semelhante. $O$ amor de si - um tema abordado com freqüência por Agostinho e seu seguidor Jansenius ${ }^{6}$ exprime em Pufendorf um conceito positivo, pois indica a autoconservação do indivíduo e da espécie abordada de modo ainda incipiente por Hugo Grotius e desenvolvida com profundidade por Hobbes 7 . Do mesmo modo, a imbecillitas representa para alguns comentadores de Pufendorf uma retomada da noção hobbesiana com a intenção de dar continuação à antropologia pessimista do filósofo inglês, da perspectiva segundo a qual o homem no estado de natureza agride os outros homens ${ }^{8}$. No entanto, como salienta Francesco Todescan, falta ao termo de Pufendorf a agressividade característica da tese hobbesiana, pois a fragilidade humana por si só não estimula a bestialidade do indivíduo no estado de natureza, um terceiro elemento vem justamente preencher este requisito, a pravitas: nela encontra-se o problema do pecado original ${ }^{9}$.

Desse modo, um dos traços mais marcantes do pensamento jurídico do setecentos é o de centrar a análise no problema do indivíduo, com o propósito de encontrar um fundamento antropológico da societas. Em

\footnotetext{
${ }^{4}$ LAURENT, P., Pufendorf et la loi naturelle, Paris: Vrin, 1982, p.109.

${ }^{5}$ Cf. WELZEL, H., La Dottrina Giusnaturalistica di Samuel Pufendorf. Un contributto alla storia delle idee dei secoli XVII eXVIII (trad. de V. Fiorillo), Torino: G. Giappichelli Editore, 1993, p.73.

${ }^{6}$ Cf. TODESCAN, F., Le Radici Teologiche de Giusnaturalismo Laico. II problema della secolarizzazione nel pensiero giuridico di Samuel Pufendorf, Milano: Giuffrè Editore, 2001, p.27.

${ }^{7}$ Cf. HOBBES, T., Leviathan, Cambridge: Cambridge University Press, 1996, p.XIV.

${ }^{8}$ Cf. BRUFAU PRATS, J., La Actitud Metódica de Pufendorf y la Configuracion de la "Disciplina J uris Naturalis", Madrid: IEP, 1968, p.99ss., e PALLADINI, F., Samuel Pufendorf Discepolo di Hobbes, Bologna: II Mulino, 1990, p.135ss.

${ }^{9}$ Cf. TODESCAN, F., Le Radici Teologiche del Giusnaturalismo Laico, p.28.
} 
Pufendorf tal fundação é realizada a partir do substrato ontológico, cujo núcleo mais profundo da investigação política acaba por radicalizar-se. Para o jurista saxão, a análise obstinada do entia moralia representa o verdadeiro tecido conectivo no qual toma forma a idéia de homem. $E$ a sociabilidade dessa consolidação constitui o momento privilegiado. Esta idéia de sociabilidade, carregada de sentidos e repleta de ressonâncias de uma rica tradição, adquire no autor luterano configuração e papel autenticamente centrais. Com estilo igualmente repetitivo, o tema é trabalhado exaustivamente tendo como pano de fundo as aguçadas páginas de Hobbes sobre a noção de autoconservação. A social itas pufendorfiana, de fato, não é derivada da concepção aristotélica do "homem é por natureza um animal político" oriunda do naturalismo organicista da noção de comunidade política desenvolvida pela escolástica ${ }^{10}$, pois entre a societas e a civitas, marcada pel o vínculo contratualista, interpõem-se uma sutil e tenaz distinção ${ }^{11}$. Na descrição e afirmação da sociabilidade falta a alusão precisa ao caráter político organizado, enquanto se divisa firmemente o arranjo das relações humanas pré-políticas ${ }^{12}$.

Seguindo a mesma linha de argumentação de vários autores antigos e modernos, Pufendorf parte do que poderíamos chamar uma antropologia pessimista que considera o homem tal como ele é de modo negativo, essencialmente corrupto, débil e inapto para viver só, um sujeito frágil se o comparamos aos animais. Sua incapacidade para se desenvolver sozinho, sem a ajuda de outros, se deve à divisão desigual de suas habilidades: a maioria dos indivíduos não sabe fazer os utensílios necessários para uma vida confortável e digna, poucos homens sabem fazer de tudo um pouco, dominam a arte da confecção dos calçados e vestimentas, da culinária e da construção de moradias.

Neste ponto, alguns comentadores importantes ressaltam a influência desempenhada pela antropologia negativa de Hobbes na teoria de Pufendorf. A razão principal a favor da recepção hobbesiana pode ser descrita dessa forma: "No estado de natureza, os indivíduos estão originariamente centrados sobre a singularidade, e não relacionados com outra coisa. Se

\footnotetext{
${ }^{10}$ Cf. PALLADINI, F., Samuel Pufendorf Discepolo di Hobbes, p.157.

${ }^{11}$ Catherine Larrère insiste na assimilação da sociabilidade à lei fundamental do direito natural, é mesmo a base de sua sistematicidade (cf. LARRĖRE, C., L'invention del'économie au XVIII e siècle. Du droit nature à la physiocratie, Paris: PUF, 1992, p.24). Isso, porém, não significa afirmar que a socialitas se confunde com a existência das sociedades civis. Quando Pufendorf afirma que o homem é destinado a viver em sociedade, não diz que ele tem uma inclinação natural para a sociedade civil, para o Estado. Pufendorf rejeita a idéia aristotélica do "homem é por natureza um animal político" (ARISTÓTELES, 1253 a 2-5), ao separar o vínculo social (universal) e a obrigação política (no interior das sociedades particulares) e distinguir entre a generalidade da regra (que impõe a sociabilidade) e o motivo da formação das sociedades particulares.

${ }^{12}$ Cf. MANCINI, O., Diritto naturale e potere civile in Samuel Pufendorf, in G. Duso, ed., II Contratto Sociale nella Filosofia Politica Moderna, Milano: FrancoAngeli, 1998, p.120.
} 
eles entram em al guma forma de sociedade, isso não se deve a um impulso natural irresistível nem à busca da virtude, mas a um cálculo que visa à utilidade individual. Na medida em que a sociabilidade do homem é finalizada à conservação de si, ele é, paradoxal mente, profundamente egoísta. A mesma definição da lei de natureza, lugar fundamentalmente de todo o direito natural, mostra explicitamente que a necessidade de sociedade é uma conseqüência da necessidade de conservação e que, portanto, o verdadeiro princípio do direito natural é a autoconservação do indivíduo"13. Duas teses importantes podem ser retiradas do comentário de Mario Scattola: 1) embora Pufendorf atribua à sociabilidade humana uma função central (primeira lei de natureza), o seu papel não implica absolutamente que os homens sejam sociais e o corpo político seja "co-essencial" ao homem, o que poderia sugerir a existência de indivíduos fora da sociedade. Para o comentador, "o princípio de sociabilidade tem, com efeito, um valor exclusivamente epistemológico: é o fundamento lógico que permite a dedução do conjunto jusnaturalista" ${ }^{14}$. Desse modo, a sociabilidade não é uma característica intrínseca dos homens, mas uma "ficção lógica" compartilhada por todos que faz das normas do direito natural um produto da razão e uma conquista a partir das determinações fundamentais da natureza humana. 2) sugere a presença de um traço paradoxal na doutrina de Pufendorf, qual seja, "a sociedade humana nasce da sociabilidade natural do homem, mas é fundada recorrendo a um segundo princípio, a imbecillitas, ou seja, a insegurança do direito e, em última instância, o interesse individual" 15 . O vínculo de parentesco é insuficiente e restrito às relações afetivas dos pequenos grupos domésticos, e as pessoas fora deste círculo limitado são consideradas pouco confiáveis e inimigas declaradas. Os homens no estado de natureza, portanto, não se ajudam mutuamente e são presas fáceis do "desejo de se prejudicarem": impera entre eles a suspeita perpétua, a desconfiança mútua e o desejo de prepotência "de forma que só é verdadeiramente feliz quem vê no amigo um inimigo em potencial" e "em tempo de paz pensa na guerra". Estranha felicidade a de levar vantagem sobre tudo e sobre todos, a de ser reconhecido como mais forte e astuto e viver da produção de conflitos com seus semel hantes. Sem explorar plenamente aqui as teses de Scattola, aliás, retomadas de Jaime Brufau Prats e Fiammetta Palladini, e suas influências hobbesianas, que por si só são controversas, limito apenas em descrevêlas e sugerir um pouco de prudência na recepção da tese de "Pufendorf discípulo de Hobbes", pois não faltam elementos teóricos sugerindo uma natureza

13 SCATTOLA, M., Ordem e imperium: das políticas aristotélicas do começo do século XVII ao direito natural de Pufendorf, in DUSO, G. (ed.), O Poder. História da Filosofia Política Moderna (trad. de A. Ciacchi, L. C. Silva e G. Tosi), Petrópolis: Vozes, 2005, p.104.

14 Ibidem, p. 105.

15 Ibidem. 
humana boa e pacífica e comentadores dispostos a sustentá-la ${ }^{16}$, pois se há uma lei da natureza como ditame da reta razão que pode ser deduzida da natureza do homem, é preciso que o homem seja sociável e disposto a unir-se a outros como ele, conduzir-se de tal modo que possam sentir motivação pela mútua preservação e aumento da boa fortuna ${ }^{17}$.

A pesar dos argumentos em contrário, Pufendorf reconhece que a verdadeira natureza do homem não é a do bom selvagem caído das nuvens, abandonado a si mesmo sem o auxílio de Deus e dos outros homens, mas um misto de maldade, petulância e irritação. A massa dos homens, sugere Pufendorf, ordena sua vida pelo impulso e não pela razão: “O homem é um animal extremamente desejoso da própria preservação, por si só necessitado, incapaz de existir sem a ajuda de seus semel hantes, adaptados de maneira notável a promover vantagens recíprocas, e, ao mesmo tempo, é maldoso, malicioso, suscetível e capaz de infringir prejuízos aos outros. Por isso, para salvar-se ele deve necessariamente ser social"18. Mas se a

${ }^{16} \mathrm{Em}$ geral, o jusnaturalismo moderno é unânime no combate da idéia de um direito de natureza que seria potência ou força. "Pufendorf, contra Hobbes, se junta a Grotius para ver no direito natural não uma potência física quantificável, mas uma qualidade moral que se avalia no homem em vista de sua natureza racional" (GOYARD-FABRE, S., Os Fundamentos da Ordem J urídica (trad. de C. Berliner), São Paulo: Martins Fontes, 2002, p.58). Tese semelhante é defendida por T. J . Hochstrasser: "Against Hobbes, Pufendorf is eager to maintain that concern for self-preservation is not incompatible with Grotius' sociability thesis" (HOCHSTRASSER, T. J., Natural Law Theories in the Early Enlightenment, Cambridge: Cambridge University Press, 2000, p.63). Sobre uma posição que ressalta a crítica de Pufendorf às teses de Hobbes do estado de natureza, cf. GOYARDFABRE, S., Pufendorf et le droit naturel, Paris: PUF, 1994, p.65-77. A despeito das críticas de Pufendorf ao filósofo de Malmesbury, não se pode negar a influência profunda do seu voluntarismo que o afasta de Grotius. Hans Welzel escreve: "Nel fatto l'esistenza di un diritto naturale razionale dipende dal sussistere di una Idea razionale di uomo. Quando questa viene meno, ne resta scossa la base di un diritto naturale razionale. Pufendorf, contestando per I'uomo un concetto razionale della sua essenza, elimina lui stesso il fondamento di un diritto naturale genuinamente razionale" (WELZEL, H., Diritto naturale e giustizia materiale (trad. italiana), Milano, 1965, p.207). Simone GoyardFabre fala em uma bifurcation philosophique, que impõe uma heterogeneidade complexa às teorias jusnaturalistas do século XVII. Por um lado, o racionalismo de Grotius, por outro, o voluntarismo de Pufendorf (cf. Goyard-Fabre, S., Pufendorf et Grotius: deux faux amis ou la bifurcation philosophique des théories du droit naturel, in FIORILLO, $V$. (ed.)., Samuel Pufendorf Filosofo del Diritto e della Política, Napoli, La Città del Sole, 1996, p.171).

${ }^{17}$ Cf. LAURENT, P., Pufendorf et la loi naturelle, p.109; e Hunter, I., Rival Enlightenments. Civil and Metaphysical Philosophy in Early Modern Germany, Cambridge: Cambridge University Press, 2001, p.157-158.

${ }^{18}$ Texto latino completo: "Scilicet manifesto adparet, hominem esse animal sui conservandi studiosissimum, per se egenum, sine sui similium auxilio servari ineptum, ad mutua commoda promovenda maxime idoneum; idem tamen saepe malitiosum, petulans, \& facile irritabile, ac ad noxam inferendam promtum, ac validum. Ejusmodi animali, ut salvum sit (bonisque fruatur, quae in ipsius conditionem heic cadunt,) necessarium est, ut sit sociabile, id est, ut conjungi cum sui similibus velit, $\&$ adversus illos ita se gerat, ut ne isti ansam accipiant eum laedendi, sed potius rationem habeant ejusdem commoda servandi, aut promovendi" (PUFENDORF, S., Gesammel te Werke, Band 4.1, II, III, §15). 
maioria dos homens não orienta as ações conforme a reta razão, é estúpida e má pela própria natureza, como podem ser deduzidos os princípios do direito natural a partir da natureza humana? Como explicar este dilema? Talvez a resposta esteja contida na própria contradição inerente às doutrinas do direito natural, na defesa simultânea dos dois lados da natureza humana, da natureza fundamentalmente boa do homem como a fonte do direito natural ${ }^{19}$ e da justificação pela maldade do homem da necessidade do direito positivo com seu mecanismo coercitivo. Mais exatamente, não é suficiente dizer que o homem é levado pela própria natureza a entrar em sociedade e que ele não pode nem quer ficar fora dela, mas enquanto um animal que ama a si mesmo e o usufruto das coisas, o homem, mesmo que busque espontaneamente a sociedade, quer ter certeza de auferir alguma vantagem - egoísta, os valores morais das ocupações de utilidade dos indivíduos não incluem as preferências de outros, ou ao menos daqueles com quem eles interagem ${ }^{20}$. Uma resposta possível à aparente contradição éa que aponta, portanto, para as duas facetas da dedução pufendorfiana do direito natural. Segundo Brufau Prats: "N os encontramos diante de uma antropologia que bebe em duas fontes diversas, mas que deseja desembocar numa harmonização sintética, fazendo da 'socialitas' e da 'imbecillitas' dimensões ontologicamente radicadas na natureza do homem" ${ }^{21}$.

A pesar disso, podemos defender com algum grau de certeza a tese segundo a qual o homem é um ser destinado a conviver socialmente para que os demais comam e satisfaçam todas as necessidades e exigências básicas da condição humana, e é improvável, admitindo-se esta hipótese, que sozinho ele realize estas funções mínimas. O homem solitário não é um indivíduo autônomo, mas sim um sujeito vulnerável ${ }^{22}$. As necessidades de companhia, sobrevivência e viver melhor impulsionam o homem a associar-se para construir mutuamente uma sociedade onde todos coloquem em comum seus escassos saberes, habilidades e muitas necessidades. Produto da associação aleatória e coincidência temporal de interesses renovados

\footnotetext{
${ }^{19}$ Pufendorf parece uma vez mais "retificar" (TERREL, J., Les théories du pacte social. Droit naturel, souveraineté et contrat social de Bodin à Rousseau, Paris: Seuil, 2001, p.306-307) as teses de Hobbes: o estado de natureza não é por si mesmo um estado de guerra e o homem é um ser racional, "que, mesmo no estado de natureza, tem um critério de avaliação comum, seguro e constante: a natureza das coisas, que indica do modo mais fácil e acessível os preceitos gerais da vida e da lei natural." ["Atque hoc quoque respectu ille status nomine naturalis libertatis venit, dum quilibet citra antegressum humanum factum sui juris potestatisque, ac nullius alterius hominis potestati subjectus esse intelligitur"] (PUFENDORF, S., Gesammelte Werke, Band 4.1, II, II, §3).

${ }^{20}$ Cf. PUFENDORF, S., Gesammelte Werke, Band 4.1, II, V, §2.

${ }^{21}$ BRUFAU PRATS, J., La Actitud Metodica de Pufendorf y la Configuracion de la "Disciplina J uris Naturalis", p.56.

${ }^{22}$ Cf. DENZER, H., Moral philosophie und Naturrecht bei Samued Pufendorf. Eine geistesund wissenschaftsgeschichtliche Untersuchung zur Geburt des Naturrechts aus der praktischen Philosophie, Müchen: C. H. Beck, 1972, p.92-93.
} 
pelas preferências individuais, a sociedade converte-se em realidade a partir da admissão de todos da necessidade absoluta por uma vida gregária. Em outras palavras, o estado de natureza, a sociedade em que todos são felizes (em teoria, pelo menos) precisa ser modificado quando o homem decide se unir a outros ${ }^{23}$. Nas palavras de Pufendorf: "O estado em que se concebe o homem assim como é constituído desde o seu nascimento, abstraindo, portanto, as invenções e as instituições, sejam humanas, sejam inspiradas pela divindade, que deram à vida dos mortais um aspecto novo e diferente. Dentre estas, incluímos não só as diferentes artes e todo o processo de formação do homem, como também e, sobretudo as sociedades civis, que, ao surgirem, organizaram o gênero humano em uma ordem harmônica" ${ }^{24}$. Portanto, a natureza do homem e de sua interação comunitária conduz necessariamente ao estabelecimento do Estado: “É tamanha a estupidez da maioria dos homens e a violência das suas paixões, que apenas bem poucos conferem a estas questões a consideração que lhes é devida. Portanto, não restou nenhum remédio mais eficaz para conter a maldade dos homens que o fornecido pelos Estados"25. Estamos diante da concepção da

\footnotetext{
${ }^{23}$ A felicidade no estado de natureza está reduzida às relações simples e pacíficas dos homens, pois, ao fazer abstração da invenção das artes e das sociedades políticas, o homem para Pufendorf se encontra em total despojamento e miséria. Retomando o gesto de Hobbes, Pufendorf reivindica o direito de representar a constituição primitiva do homem fazendo abstração da Revelação: ele pode assim citar as descrições de Horácio e Lucrécio. Não estamos, porém, diante de uma reconstrução hipotética das origens da humanidade, mas de uma experiência mental visando demonstrar que os homens têm necessidade de seus semel hantes. Os cristãos sabem o que Horácio e Lucrécio ignoravam: "por um efeito inteiramente particular da Providência divina", os primeiros homens aprenderam as artes mais necessárias para a sobrevivência. Contudo, o nascimento e o desenvolvimento das artes não bastam para proteger os homens da miséria, pois na ausência da sociedade civil a própria vida civilizada está ameaçada. É preciso sublinhar a separação entre a construção mental do estado puramente natural, em que todos os homens não teriam outra relação na ausência de qualquer convenção ou instituição, a não ser a que resulta da semelhança de suas naturezas, e as situações históricas reais em que os homens estão agrupados em famílias independentes ou sociedades particulares. Para encontrar a realidade a partir da "ficção" é preciso "temperar" o estado puramente natural e considerar as relações entre as sociedades civis.

${ }^{24}$ Texto latino: "Per statum hominis naturalem non intelligimus heic illam conditionem, quam velut perfectissimam, $\&$ homini quam maxime congruentem natura ultimo intendit; sed in qua homo per ipsam nativitatem constitutus concipitur, prout abstracta intelliguntur inventa, atque instituta humana, (aut homini divinitus suggesta), quibus aliam velut faciem vita mortalium induit. Sub quibus comprehendimus non solum varias artes, \& universum vitae humanae cultum, sed etiam potissimum societates civiles, quarum exortu genus humanus in concinnum ordinem fuit digestum" (PUFENDORF, S., Gesammelte Werke, Band 4.1, II, II, §1).

25 Texto latino: "Stoliditas tamen plerumque hominum, \& affectuum vehementia facit, ut ista omnia paucissimis pro dignitate considerentur. I gitur fraenandae hominum pravitati efficacius remedium non supererat, quam quod civitates jam constitutae suppeditant" (PUFENDORF, S., Gesammelte Werke, Band 4.2, De jure naturae et gentium (Liber quintus - Liber octavus), herausgegeben von F. Böhling, Berlin: Akademie Verlag, 1998, VII, I, §11).
} 
sociedade composta por elementos justapostos que têm carências de toda ordem e espécie. Ela não é a comunidade do ideal político aristotélico, mas a conjunção harmonizada de elementos diferentes num mesmo espaço e durante um tempo determinado. Mais ainda, a sociedade não é o produto do instinto sociável, psicológico, construído a partir da ordem física (appetitus societatis). Ela é um dever ${ }^{26}$. Separada de modo radical dos "seres físicos", a doutrina dos "seres morais" (entia moralia) parece contradizer o naturalismo de Hobbes e de Spinoza e se vincular às fórmulas incertas de Grotius ${ }^{27}$. Mas enquanto neste último o appetitus societatis é um impulso da natureza humana e a vida social flui como sua conseqüência natural, em Pufendorf a exigência da imbecillitas faz aflorar uma socialitas que permite deduzir o conteúdo mais profundo da vida associativa. Onde em Grotius se manifestava um impulso, em Pufendorf se distingue o objetivo regulador ${ }^{28}$. Em suma, a "antropologia bifronte" de Pufendorf pretende conseguir a "harmonização sintética" de dois relevantes perfis da natureza humana. No máximo, o jurisconsulto admite um appetitus societatis restrito às comunidades pequenas, como a amizade, 0 matrimônio e a família, mas não ao Estado 29 . A relação entre a socialitas e o appetitus socialis se configuraria desse modo: a sociabilidade seria a categoria objetiva do valor do agir ético-social, isto é, constituiria o conteúdo da lei natural. As causas vitais ou psicológicas (causae impulsivae) da atuação da lei natural seriam a conviç̧ão de seu valor e o temor diante de Deus; para as comunidades pequenas, o appetitus societatis, para o Estado, o temor dos outros homens ${ }^{30}$.

A natureza corrompida do homem, suas necessidades e sua falta de idoneidade para assumir a organização social e interagir segundo os limites da lei natural, o leva a viver em sociedade. Tese paradoxal, mas que marca a inovação de Pufendorf e a estreita ligação com os fenômenos históricos de seu tempo ${ }^{31}$. O caráter deficiente dos homens demonstraria historicamente que a convivência é complicada, quando não improvável. A guerra dos Trinta Anos e todos os conflitos bélicos promovidos pelos homens na história seriam bons e eloqüentes exemplos. A convivência exige a impo-

\footnotetext{
${ }^{26} \mathrm{O}$ que surpreende nesse passo do autor, é que Pufendorf inaugura uma tradição interpretativa mais próxima da segunda metade do século $X X$, ao negligenciar a ordem da dedução hobbesiana (da liberdade à obrigação) e transformar o direito natural em obrigação racional de se conservar, elevando a lei e não o direito ao lugar de destaque (cf. GOYARD-FABRE, S., Pufendorf et le droit naturel, p.56-60).

${ }_{27}$ Cf. GROTIUS, H., Do Direito da Guerra e da Paz (trad. de C. Mioranza), Ijuí: Editora UNIJ UÍ/Fondazione Cassamarca, volume 1, 2004, Prolegômenos, §§7-8.

${ }^{28}$ Cf. WOLF, E., Grotius, Pufendorf, Thomasius. Drei Kapitel der Gestaltgeschichte der Rechtswissenschaft, Tübingen: J . C. B. Mohr, 1927, p.89-90.

${ }^{29}$ Cf. PUFENDORF, S., Gesammelte Werke, Band 4.2, VII, I, §3.

30 Cf. WELZEL, H., La Dottrina Giusnaturalistica di Samuel Pufendorf, 74.

${ }^{31}$ Cf. KRIEGER, L., The Politics of Discretion. Pufendorf and the acceptance of natural law, Chicago: The University of Chicago Press, 1965, p.170-178.
} 
sição inflexível dos deveres e obrigações de inexorável cumprimento ${ }^{32}$. Deveres que adquirem o fundamento no próprio modo de ser do homem, isto é, que o homem deve observar pelo mero fato de ser homem (algo como uma imposição da natureza). Este é, aliás, o conteúdo do Livro primeiro do De officio. No Livro segundo Pufendorf desenvolve a dedução dos deveres artificiais que emanam das relações estabelecidas e vividas pelos homens em diversas posições sociais: estado de natureza, família, unidade econômica - senhor e escravo - e sociedade civil politicamente organizada e devidamente hierarquizada. Só com a estrita observação destes deveres básicos e universais, o homem pode chegar a ser um membro útil para a sociedade na qual está inserido. Dessa forma, Pufendorf acredita que pode construir um regime político estável, garantindo seu desenvolvimento legítimo ao oferecer razões suficientes aos homens para cuidarem de si mesmos, da sociedade em que vivem e do regime político que os governa.

Considerando o esquema antropológico e social de Pufendorf, o homem solitário e frágil por natureza se converte no homem do homem na sociedade, pois da união de diversas habilidades físicas e espirituais é possível superar a própria debilidade. A união dos indivíduos representa muito mais do que a soma aritmética de todos, supõe um salto de qualidade de proporções geométricas, cujas debilidades são minimizadas e as poucas habilidades sofrem uma otimização impossível na solidão do estado de natureza. Este nível de transformação, porém, só é alcançado mediante uma renúncia: a liberdade é trocada pela imposição do poder externo. $\mathrm{O}$ súdito se submete para viver melhor do que vivia no estado de natureza. Ele pode viver melhor por imposição externa, mediante a criação de um poder mais forte que exige a submissão total, ou por intermédio do acordo mútuo de pessoas que se reconhecem como iguais, pessoas detentoras de certos princípios morais e jurídicos que permitem viver conjuntamente. No primeiro caso, os deveres são cumpridos por coação superior; no segundo, os deveres surgem de maneira natural e são matizados por princípios comuns e internos a todos os homens. Pufendorf escreve: "Há duas causa que tornam o homem apto para assumir uma obrigação: ele tem uma vontade capaz de inclinar-se para vários sentidos, e por isso de se conformar a alguma regra; ele é vulnerável e depende de um superior"33. E acrescenta: “(...) é capaz de obrigação quem tem um superior, pode reconhecer uma norma prescrita e tem uma vontade inclinada para vários

\footnotetext{
32 Pufendorf identifica três campos principais: os deveres para com Deus, para com o próximo e para consigo mesmo.

33 Texto latino: "Quod autem homo aptus fit ad recipiendam obligationem, duplex causa est: una quidem, quia is voluntatem habet, quae sese in diversas partes flectere, adeoque $\&$ ad normam componere potest: altera, quia homo a potestate superioris non est immunis" (PUFENDORF, S., De Officio Hominis et Civis J uxta Legem Naturalem Libri Duo, Introduction by Walther Schücking, New York: Oxford University Press, The Classics of International Law, 1927, I, II, §4).
} 
sentidos; no entanto, quando foi prescrita uma norma por um superior, deve estar convencido que se separar dela não é correto. Desta natureza parece dotado o homem" 34 .

Com habilidade, Pufendorf se move entre as duas possibilidades e afirma que nem todas as obrigações são voluntárias: há muitas que são impostas ao agente da ação ${ }^{35}$. Os deveres que não são voluntários têm origem e fundamento na imposição de alguém com poder e superioridade suficientes para fazêlo. Para Pufendorf não há propriamente maldade no procedimento de quem utiliza com autoridade o poder para impor regras de conduta, podendo caracterizar algo de lesivo à pessoa submetida; imediatamente o jurisconsulto se encarrega de explicar os efeitos benéficos da submissão e obediência aos mandamentos dos superiores, e as condições exigidas para o estabelecimento de novas e imprescindíveis obrigações responsáveis pela garantia de existência da própria sociedade onde vivem $^{36}$. Eis o motivo da conversão do indivíduo subordinado em um membro útil à sociedade. Pufendorf deduz o seguinte da situação apresentada: o direito natural é justificado a partir da noção de socialitas, pois é comum, geral e constante na humanidade ${ }^{37}$. Assim, para al cançar a segurança almejada pelo indivíduo no convívio com os outros, é necessário que o homem reconheça este caráter imprescindível, qual seja, que o "homem é um animal comunitário, porque ele, diversamente de outros seres vivos, é capaz de estruturar confortavel mente sua vida, não havendo nenhum outro capaz de fazêlo" ${ }^{38}$. Os deveres para consigo mesmo o levam ao edificante exercício da boa vontade para alcançar o bem e a virtude, à aspiração de bens exteriores e posses no limite do socialmente defensável, e à boa vida cidadã e em concordância com o costume burguês ${ }^{39}$.

Para se chegar a esta real idade, porém, o homem põe em movimento a sua paixão mais intensa, o amor de si (amor sui) e a necessidade de autoconservação. Este movimento acrescenta razões poderosas para se preservar a vida. A imbecillitas ou debilidade física e mental do homem impede a garantia da sobrevivência, impossibilitando assim a segurança e os meios necessários para o desenvolvimento satisfatório das capacidades

\footnotetext{
34 Texto latino: “(...) ut ille obligationis sit capax, qui \& superiorem habet, \& normam praescriptam potest cognoscere, $\&$ voluntatem habet in diversa flexibilem; quae tamen ubi norma per superiorem fuerit praescripta, sentiat se ab ipsa non recte discedere. Quali natura hominem praeditum adparet" (I bidem).

35 I bidem, I, II, §1; I, II, §11.

36 Ibidem, I, III, §10.

37 I bidem, I, III, §§1-7.

${ }^{38}$ Texto latino: "(...) ideo animal sociabile hominem diximus, quod homines mutua commoda, magis quam ullum aliorum animantium, promovere idonei sint" (PUFENDORF, S., Gesammel te Werke, Band 4.1, II, III, §16).

39 Isto significa, por um lado, "divertimento e deleite" (ibidem, II, IV), e, por outro, participação na formação, conhecimento e prática das belas-artes.
} 
sociáveis do indivíduo. Portanto, o homem se vê na dependência do outro por um interesse menos nobre do que o defendido por Aristóteles, qual seja, a debilidade física e mental, a fal ta de habilidade que se manifesta na necessidade imperiosa de deixar o estado de natureza e construir uma sociedade. Da paixão pela conservação da vida, passamos a mendigar um lugar que garantisse a integridade física e o desenvolvimento vital ${ }^{40}$. 0 amor de si é o impulso mais forte em busca da segurança vital na sociedade, é ele que assegura os meios necessários para conservar a vida. É um impulso que os homens não podem evitar: "Há algo de comum entre o homem e os animais com algum conhecimento e sentimento de si mesmos, pois eles amam a si mesmos intensamente e trabal ham com todos os meios na conservação, na busca do que Ihes parecem bom e na fuga daquilo que pode prejudicá-los" ${ }^{41}$. Esta tendência natural deve se limitar e harmonizar com a necessidade de viver coletivamente, porque sem os outros os homens perderiam as sua vidas. Somente a partir disso a sociabilidade pode ser vista como uma obrigação que impõe o essencial da natureza humana; trata-se, em última instância, de um mandamento divino cuja obrigação moral é imposta: “O bom senso nos dita, não apenas que a observação das leis naturais é vantajosa ao gênero humano, mas ainda que Deus quer e ordena aos homens tomarem as leis por normas de suas ações" ${ }^{42}$.

A simples convivência com os outros não é requisito suficiente para se alcançar a perfeição onde existiria defeitos, males e situações difíceis. A sociedade composta por estranhos, que tem como denominador comum a debilidade e a necessidade humanas, não pode de nenhuma forma garantir a felicidade do sujeito que se agrega a ela. A vida em comum não supõe apagar e superar simplesmente os defeitos de cada um - que também fazem parte do modo de ser do indivíduo -, mas criar as condições para que os defeitos não predominem e se convertam em dificuldades insuperá-

\footnotetext{
${ }^{40}$ Para Vanda Fiorillo, o princípio de sociabilidade acaba por se configurar como ancorado em um componente egoísta e apropriador, ou seja, como pólo de conversão do amor sui natural em um egoísmo prudente e racionalmente regulado: "L'amor sui e la socialitas - lungi dal porsi come principî confliggenti - instaurano la piena coincidenza degli interessi privati con quelli comuni, in una perfetta armonia sociale, in cui i ruoli interdipendenti dei singoli individui contribuiscono a promuovere l'interesse collettivo" (FIORILLO, V., Tra Egoismo eSocialità. II Giusnaturalismo di Samuel Pufendorf, Napoli: J ovene Editore, 1992, p.48). Esta conversão lógica já havia sido defendida por Leonard Krieger: "As a logical consequence of weakness, sociability could, like weakness, incorporate self-love within itself" (KRIEGER, L., The Politics of Discretion, p.93).

${ }^{41}$ Texto latino: "Id igitur primo homo habet commune cum omnibus animantibus, queis sensus sui inest, ut seipsum quam máxime amet, seipsum studeat omnibus modis conservare, quae bona sibi videntur nitatur adquirere, mala repellere" (PUFENDORF, S., Gesammelte Werke, Band 4.1, II, III, §14).

${ }^{42}$ Texto latino: "Sane enim ex dictamine rationis non intelligitur solum, legum naturalium observantiam esse generi humano proficuam, sed \& DEUM velle ac jubere, ut mortales ad istarum normam actiones suas dirigant. Id quod ad essentiam legis sufficit" (ibidem, $\mathrm{I}, \mathrm{VI}, \S 4)$.
} 
veis, pois a convivência se transformaria numa luta de todos contra todos, igual a que fala Hobbes no De cive ${ }^{43}$. A forma de chegar a ser sociável e superar os defeitos encontra-se ao mesmo tempo na observação dos preceitos e princípios derivados do direito natural ${ }^{44}$ e na manutenção de tudo o que pode ajudar a sua conservação e desenvolvimento, desconsiderando e rechaçando tudo o que pode pô-la em perigo de destruição ${ }^{45}$.

O princípio fundamental e evidente do direito natural é que todo homem tem o dever de cultivar e preservar a sociabilidade ${ }^{46}$; esta obrigação implica a existência dos deveres numa tríplice dimensão: diante de Deus, diante de si mesmo e diante dos outros ${ }^{47}$. Mais ainda, todo homem, enquanto indivíduo, deve observar que as suas ações produzem efeitos em outras pessoas, e mediante essa tríade de obrigações atuar de modo a se chegar à condição de elemento útil à sociedade.

O primeiro dever de quem vive coletivamente está na busca incansável de todos os meios possíveis para não causar dano a nenhum outro (tese defendida também por Grotius e Hobbes). Mas ficar aí somente não basta: a busca incansável seria insuficiente. O homem também precisa eliminar os meios e as ocasiões propícias a provocar uma reação anti-social, isto é, deve atuar visando os outros, respeitando a dignidade e a igualdade de cada um, e evitar qualquer tipo de injúria e dano aos demais: "que cada um estime e trate o outro como naturalmente igual a ele ou como igualmente homem" 48 . Desta afirmação, porém, Pufendorf deduz o segundo dever: a sociedade - já não considerada comunidade - deve se fundamentar no reconhecimento mútuo da igual dignidade de todos os homens, algo oposto ao domínio de uns sobre os outros como ocorria em épocas passadas. Para manter a sociedade unida e seus membros vivendo em harmonia

${ }^{43}$ Cf. HOBBES, T., Elementorum Philosophiae Sectio Tertia, De Cive, in Opera Philosophica quae Latine Scripsit, Vol. II, W. Molesworth, London: J ohann Bohn, 1839, I, 2.

${ }^{44}$ Cf. PUFENDORF, S., Gesammelte Werke, Band 4.1, II, III, §15.

${ }_{45}$ Pufendorf define a justiça sob o direito natural como a "vontade perpétua de dar a cada homem o que Ihe é devido" ["perpetuam voluntatem habuerit cuique tribuendi, quod ipsi debetur"] (PUFENDORF, S., Gesammelte Werke, Band 3, Elementa jurisprudentiae universalis, herausgegeben von T. Behme, Berlin, Akademie Verlag, 1999, XVII, §1). Além da presença forte da jurisprudência romana na formulação de Pufendorf, há um acréscimo importante do autor, qual seja, algo só pertence a uma pessoa (tem uma base legal num direito perfeito) se ela puder mover uma ação contra o agressor em um tribunal humano (ibidem, VIII, §2). Embora a justiça seja definida pelo direito natural, ela só é possível sob o direito positivo (para a distinção entre direitos perfeitos e direitos imperfeitos, cf. PUFENDORF, S., Gesammel te Werke, Band 4.1, I, VII, §7).

${ }^{46}$ Cf. PUFENDORF, S., Gesammelte Werke, Band 4.1, II, III, §20.

${ }^{47}$ Cf. PUFENDORF, S., De Officio Hominis et Civis J uxta Legem Naturalem Libri Duo, I, IV e I, V.

${ }^{48}$ Texto latino: "ut quisque alterum hominem aestimet atque tractet, tanquam naturaliter sibi aequalem, seu ut aeque hominem" (ibidem, I, VII, §1). 
é preciso conseguir que o dever de benevolência - o terceiro dever - prevaleça sobre os outros ${ }^{49}$.

O respeito, a igual dignidade e a benevolência são três deveres que servem para justificar as obrigações nas ações políticas e nos atos jurídicos praticados pelos indivíduos na sociedade: contratos, pactos, compra e venda de propriedades, doações, heranças, e todo tipo de relações em geral que tem como instrumento a linguagem. Mas também delas derivam as obrigações próprias do indivíduo como membro de uma família e de um Estado.

Estes três deveres são importantes. Uma vez mais Pufendorf parece seguir Sêneca, quando o filósofo latino afirma que as paixões mais odiosas e mais detestáveis são a injustiça e a ingratidão: ambas levam irremediavelmente à dissolução da sociedade e à loucura de seus habitantes ${ }^{50}$. Desse modo, para Pufendorf a sociabilidade se converte no fundamento do direito natural, e também na justificação da existência e do desenvolvimento da sociedade humana. O homem dentro da coletividade tem certas obrigações a cumprir: é mediante a observação delas que chega a ser útil para todos, pois realiza a sociabilidade, preserva a segurança e garante o bem viver social. A conclusão de Pufendorf é que as obrigações derivadas da sociabilidade têm como fim buscar e al cançar a conservação e o desenvolvimento da sociedade ao evitar as injustiças e a ingratidão ${ }^{51}$. Não é de se estranhar, portanto, que a primeira obrigação do homem é ser útil à sociedade como membro dela, promovendo assim o seu desenvolvimento social, econômico, político e cultural.

Admitindo-se que há vários componentes de uma antropologia pessimista na filosofia moral de Pufendorf, pode-se dizer que o autor demonstraria nitidamente a dificuldade do homem em alcançar por si mesmo a realização das obrigações recorrendo unicamente aos seus possíveis benefícios por em movimento por vontade própria uma busca de padrões morais razoáveis mediante as suas vantagens. Desse modo, o sistema ou a teoria da sociabilidade, fundamento da construção teórica de Pufendorf, exige um desenvolvimento e justificação posterior, que se oferecem nos livros segundo do D e officio e sétimo do D e jure. Neles o autor explica os meios mais eficazes para suprimir as más ações, as tendências desviantes e egoístas, os maus usos e costumes, e tudo o que pode prejudicar ao outro e à sociedade. Estes meios, aliás, já estão presentes e reconhecidos no estado de natureza, e se efetivam quando os homens decidem construir a cidade, o Estado, isto é, quando decidem viver e realizar a sociabilidade ${ }^{22}$. Em outras palavras, Pufendorf inicia com grande esforço uma abordagem te-

\footnotetext{
49 Ibidem, I, VIII.

50 I bidem, I, VIII, §8.

${ }^{51}$ I bidem, I, V; II, V, §4; II, XIII, §2 e II, XVII, §4.

52 I bidem, II, V, §9.
} 

homem nelas.

Em última instância, Pufendorf desenvolve a partir da idéia de direito natural a teoria voluntarista do contrato. No seu entender, o poder político tem uma origem racional: nasce do encontro de vontades individuais para dar 0 consentimento a um magistrado, através de um acordo. Toma-se, então, consciência de três idéias que vão influenciar o pensamento político moderno: primeira, o Estado não tem legitimidade para contrariar os direitos naturais ${ }^{53}$; segunda, o direito natural deve ser fonte do direito positivo ou construído; terceira, o homem tem uma dignidade inalienável, na medida em que, pela sua própria natureza, é sujeito de direitos. Segundo tal ponto de vista, o direito natural está, no estado de natureza, limitado ao indivíduo e pode ser reconhecido através de três fontes: a iluminação divina, a luz da razão e a voz da consciência. É válido para todos os homens, em todos os tempos e lugares, independentemente de ideologias ou crenças.

ENDEREÇO DO AUTOR:

Av. Alexandre Ribeiro Guimarães, 365 - A pto. 302

38408-050 U berlândia - MG

${ }^{53}$ Embora sustente que o direito positivo depende do direito natural, e rejeite a tese hobbesiana de que o Estado não pode causar dano a um cidadão, Pufendorf não oferece uma resposta muito animadora aos defensores do direito de resistência quando os danos provocados pelos governantes são sérios. Se num primeiro momento desobriga os cidadãos da obediência cega a uma ordem superior "repugnante ao comando de Deus", num segundo momento, porém, defende a fuga e a busca de proteção em território estrangeiro como alternativa mais aceitável. Mas, "se a fuga não for possível, um homem deve antes ser morto que matar, não tanto pela pessoa do príncipe quanto por toda a comunidade, que geralmente é ameaçada com grandes tumultos em tais circunstâncias" ["Quin \& si fugae via non datur, moriendum potius, quam occidendum est, non tam propter ipsius principis personam, quam propter totam rempublicam, quae tali occasione gravibus fere turbis solet involvi"] (PUFENDORF, S., Gesammelte Werke, Band 4.2, VII, VIII, §5). Prevalece nestes casos limites a razão de estado (đf. LARRĖRE, C., L'invention del'économie au XVIIIe siècle p.33-36; DUFOUR, A., Federalisme et raison d'Etat dans la pensée politique pufendorfienne, in FIORILLO, V. (ed.), Samuel Pufendorf Filosofo del Diritto e della Politica, p.107-138). Ainda assim, Alfred Dufour insiste no traço mais distintivo de Pufendorf, no ecletismo de seu pensamento, para se compreender a política do autor. É à luz desse ecl etismo que devemos ler o autor saxão: "Pareillement le rôle qu'elle reconnaît à la volonté dans le fondement de tout pouvoir ne permet pas de l'identifier à une première forme d'individualisme libéral, pas davantage que la sympathie qu'elle paraît nourrir à l'égard du regime monarchique ne permet de l'assimiler à quelque forme d'absolutisme opportuniste. Si I'on s'en tient aux aveux mêmes de Pufendorf, c'est bien comme une forme d'éclectisme qu'il faut considérer sa pensée" (DUFOUR, A., J usnaturalisme et conscience historique dans la pensée politique de Pufendorf, in Cahiers de philosophie politique et juridique, Caen, 1987, p.104). 